\title{
Fire Extinguishing Robot
}

\author{
Nagesh MS ${ }^{1}$, Deepika T V ${ }^{1}$, Stafford Michahial ${ }^{1}$, Dr M Shivakumar ${ }^{2}$ \\ Asst Prof, Dept of EIE, GSSSIETW, Mysuru ${ }^{1}$ \\ Prof \& Head, Dept of EIE, GSSSIETW, Mysuru ${ }^{2}$
}

\begin{abstract}
Detecting fire and extinguishing is a hazardous job for a fire extinguisher, it often risks the life of that person. This project aims in giving a technical solution to the mentioned problem. A robot is a mechanical design that is capable of carrying out a complex series of actions automatically, especially one programmable by a computer. A fire extinguisher robot is a DTMF tone controlled robot that has a small fire extinguisher unit added on to it. This mobile robot is controlled using a mobile phone through DTMF tones for its movement and reaching the fire, the flame sensor detects the fire and gives the further signal to the extinguisher units to trigger the pump and spray the water. The whole system is programmed using an arduino UNO board (ATmega328P microcontroller) which forms the brain of the system.
\end{abstract}

Keywords: DTMF technology, DC motors, flame sensor, water pump, arduino.

\section{INTRODUCTION}

Robot is a machine that looks like a human being and performs various complex tasks. There are many types of robots such as fixed base robot, mobile robot, underwater robot, humanoid robot, space robot and medicine robot etc. In this paper a FIRE EXTINGUISHING ROBOT is proposed. This robot is equipped with a single flame sensor used to sense environmental fire and feed the signals to the microcontroller in order to trigger the pump which sprinkles water in order to extinguish the fire. This robot is controlled using a mobile phone through DTMF tones decoded by the DTMF decoder. This robot implements the concepts of environmental fire sensing, proportional motor control. The motor driver is used for the bidirectional control of the motors equipped in the robot. Every instruction for motion control is given to the robot with the help of DTMF technology.

Thus, the robot processes information from its various key hardware elements such as flame sensor, DTMF decoder via Arduino Uno board (microcontroller). The programming of the robot is done using the arduino $\mathrm{C}$ which is derived from $\mathrm{C}$ and $\mathrm{C}++$ languages. This paper is presented as follows. Proposed methodology in section II which constitutes of block diagram and components and their explanation. Hardware and software details are included in section III. In Section IV, results and conclusions are included.

\section{PROPOSED METHODOLOGY}

Fig 2.1 shows the Block Diagram of Fire Fighting robot. The basic theme of this paper is to sense the environmental fire and extinguish it with the help of a water pump. The Arduino UNO Microcontroller board based on the ATmega328P. The ATmega328P is good platform for robotics application. Thus the real time fire extinguishing can be performed.

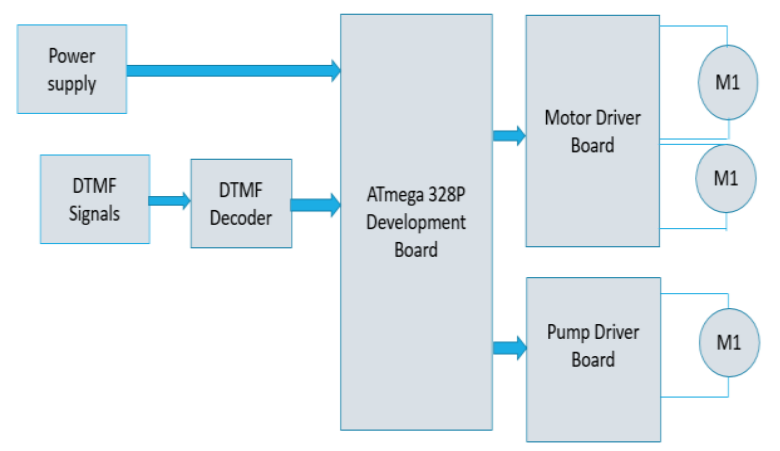

Fig 2.1: Block Diagram of Fire Fighting Robot

The Arduino software runs on different platforms such as mac, windows and Linux. Simple and clear programming is possible in case of Arduino software. The Arduino libraries play a major role in making the programming easier by providing wider range of libraries. There are many built in libraries available in the Arduino software and it allows to add additional libraries that are available in the open source for download. Adding of new boards to Arduino software is possible. Since, Arduino $\mathrm{C}$ is derived from $\mathrm{C}$ and $\mathrm{C}++$ programming and is much easier when compared other controller programming.

The microcontroller in turn control the extinguishing system. The Operating Voltage of the controller is $5 \mathrm{~V}$ and the Clock Speed is $16 \mathrm{MHz}$, and the recommended Input Voltage $7-12 \mathrm{~V}$, whereas the limitation of Input Voltage between 6-20V. The Dual-tone multi-frequency signaling (DTMF) is an in-band telecommunication signaling system which use the voice-frequency band over telephone lines between telephone equipment and other communications devices and switching centers. Here, the IC MT8870DE, a touch tone decoder IC is used. The main aim of this project is to develop a DTMF controlled fire extinguishing robot which detects the fire location and 
Vol. 5, Issue 12, December 2016

extinguish fire by using sprinklers on triggering the pump. 1100 nanometers. The test distance depends on the flame The direction of movement of the robot are described by size and sensitivity settings. The detection angle is 60 the motor driver board. It is used to give high voltage and degrees, so the flame does not have to be right in front of high current is given as an output to run the motors which the sensor.

are used in the project for the movement of the robot. In

this project a simple DC motor is used for the rotation of There are two sensor outputs the wheel which are responsible for the movement of the robot. DC motors usually convert electrical energy into mechanical energy. To extinguish the fire a pump is used to pump the water on to the flame. A simple motor is used to pump the water. The pumping motor in extinguishing system controls the flow of water coming out of pumping.

\section{HARDWARE \& SOFTWARE DETAILS}

\section{HARDWARE USED:}

\section{ATmega328P microcontroller (Arduino UNO):}

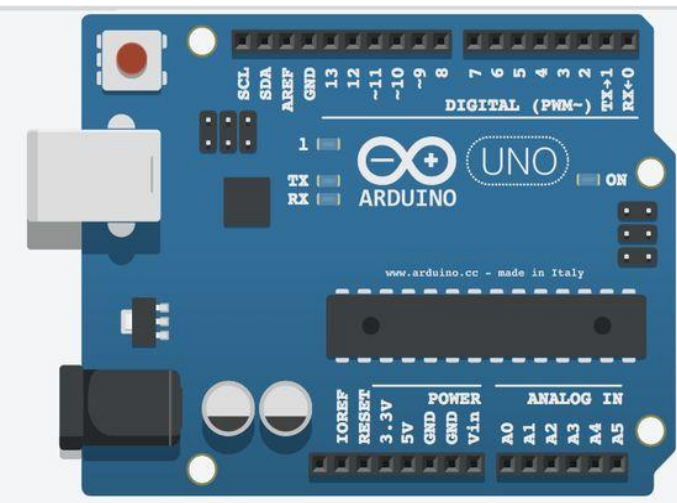

Fig 3.1: Arduino Uno microcontroller based development board

Fig 3.1 shows the arduino Uno board. Arduino/Genuino Uno is a microcontroller board based on the ATmega328P. It has 14 digital input/output pins (of which 6 can be used as PWM outputs), 6 analog inputs, a $16 \mathrm{MHz}$ quartz crystal, a USB connection, a power jack, an ICSP header and a reset button. It contains everything needed to support the microcontroller.

\section{Flame Sensors:}

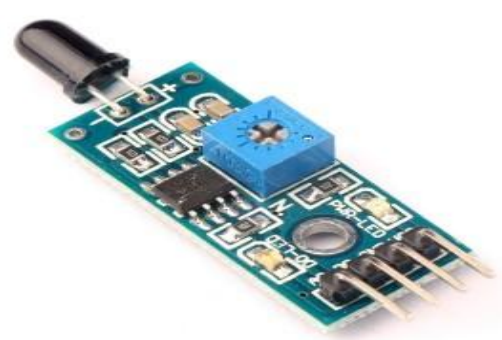

Fig 3.2: Flame Sensor

Fig 3.2 shows the flame sensor. This sensor is able to detect a flame by sensing light wavelength between $760-$ i. Digital - sending either zero for nothing detected or one for a positive detection

ii. Analog - sending values in a range representing the flame probability/size/distance; must be connected to a PWM capable input

\section{DTMF Signal and Decoder.}

Dual-tone multi-frequency signaling (DTMF) is an inband telecommunication signaling system using the voicefrequency band over telephone lines between telephone equipment and other communications devices and switching centers. DTMF was first developed in the Bell System in the United States, and became known under the trademark Touch-Tone for use in push-button telephones supplied to telephone customers, starting in $1963 \mathrm{We}$ are using the IC MT8870DE which is a touch tone decoder IC.

Table 3.1: DTMF low and high frequency tones and decoded output

\begin{tabular}{|c|c|c|c|c|c|c|}
\hline \multirow{2}{*}{ Button } & \multirow{2}{*}{$\begin{array}{c}\text { Low DTMF } \\
\text { frequency }\end{array}$} & High DTMF & \multicolumn{4}{|c|}{ Binary coded output } \\
\cline { 4 - 7 } & frequency & Q1 & Q2 & Q3 & Q4 \\
& $(\mathrm{Hz})$ & & & & \\
\hline 1 & 697 & 1209 & 0 & 0 & 0 & 1 \\
\hline 2 & 697 & 1336 & 0 & 0 & 1 & 0 \\
\hline 3 & 697 & 1477 & 0 & 0 & 1 & 1 \\
\hline 4 & 770 & 1209 & 0 & 1 & 0 & 0 \\
\hline 5 & 770 & 1336 & 0 & 1 & 0 & 1 \\
\hline 6 & 770 & 1477 & 0 & 1 & 1 & 0 \\
\hline 7 & 852 & 1209 & 0 & 1 & 1 & 1 \\
\hline 8 & 852 & 1336 & 1 & 0 & 0 & 0 \\
\hline 9 & 852 & 1477 & 1 & 0 & 0 & 1 \\
\hline 0 & 941 & 1336 & 1 & 0 & 1 & 0 \\
\hline$*$ & 941 & 1209 & 1 & 0 & 1 & 1 \\
\hline$\#$ & 941 & 1477 & 1 & 1 & 0 & 0 \\
\hline
\end{tabular}

Table 3.1 shows the DTMF low and high frequency tones and decoded output. The DTMF (Dual Tone Multi Frequency) decoder circuit identifies the dial tone from the telephone line and decodes the key pressed on the remote telephone. Here for the detection of DTMF signaling, we are using the IC MT8870DE which is a touch tone decoder IC. The decoded bits can be interfaced to a computer or microcontroller for further application 


\section{Motor Drivers:}

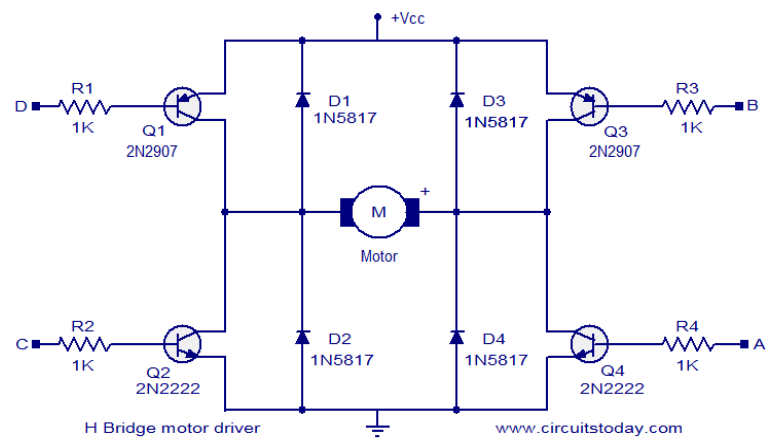

Fig 3.3: H Bridge circuit

Motor drivers are used to describe the direction of movement of the robot. It is used to give high voltage and high current as an output to run the motors which are used in the project for the movement of the robot. Fig 3.3 is the circuit of the $\mathrm{H}$ Bridge which is used for the motor driving in the IC $1293 \mathrm{D}$ and also provides the bidirectional motor control.

\section{DC Motors:}

In this project we use simple DC motor for the rotation of the wheel which are responsible for the movement of the robot. Usually DC motors convert electrical energy into mechanical energy.

\section{Pump:}

Pump is a mechanical device which is used to pump water on to the fire to extinguish it. It uses a simple motor to pump water.

\section{SOFTWARE USED:}

\section{Arduino IDE 1.6.7}

For programming the microcontrollers, the Arduino project provides an integrated development environment (IDE) based on a programming language named Processing, which also supports the languages $\mathrm{C}$ and $\mathrm{C}++$.The open source Arduino IDE makes it easy to write code and upload it to the board.

\section{RESULTS AND CONCLUSIONS}

The Fire Fighting Robot employs DTMF technology to control the directions of the robot. We design the fire detection system using flame sensor that is capable of sensing the flame of wavelength range 760 to $1100 \mathrm{~nm}$, and the sensing range depends on the sensitivity and varies from $10 \mathrm{~cm}$ to 1.5 feet.

The robot can operate in the environment which is out of human reach in very short time, the delay employed is very minimal. The robot accurately and efficiently finds the fire and within minimum time after the fire is detected it is extinguished.

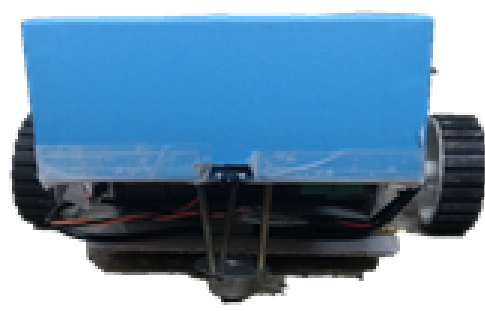

\section{REFERENCES}

[1] Control of an Autonomous Industrial Fire Fighting Mobile Robot by HP SINGH, Department of Mathematics, Sri Venkateswara College, University of Delhi

[2] An Autonomous Firefighting Robot Real Time Man-Robot Control of a Group of Specialized Mobile Robots Vassil Sgurev, Stanislav Drangajov, Lyubka Doukovska Institute of Information and Communication Technologies, 1113 Sofia

[3] A System Architecture of Wireless Communication for FireFighting Robot by Korea Advanced Institute of Science and Technology (KAIST), 335 Gwahangno, Yuseong-gu, Daejeon 305701, Republic of Korea

[4] Develop a Multiple Interface Based Fire Fighting Robot by 1Department of Electronic Engineering WuFeng Institute of Technology Ming-Hsiung

[5] FIRE FIGHTING ROBOT Sahil S.Shah1, Vaibhav K.Shah2, Prithvish Mamtora3 and Mohit Hapani4 1,2,3,4D.J.Sanghvi College of Engineering, Vile Parle - West, Mumbai, India

[6] Development of a Firefighting Robot for Educational Competitions by Taiser T. T. Barros and Walter Fetter Lages Electrical Engineering Department Federal University of Rio Grande do Sul Porto Alegre.

[7] https://www.arduino.cc/en/Main/ArduinoBoardUno

[8] http://www.slideshare.net/maastech/robotics-projects-abstractfirefighting-robot-with

[9] https://en.wikipedia.org/wiki/Arduino

[10] http://eprints.uthm.edu.my/5529/1/NOR_AYUNI_BINTI_ABD_M AJID.

[11] Joga D. Setiawan, Mochamad Subchan, and Agus Budiyono "Virtual Reality Simulation of Fire Fighting Robot. Dynamic and Motion." ICIUS, October 24-26 2007.

[12] Gerald Weed, Michael Schumacher, Shawn McVay, Jack Landes "Pokey the Fire-Fighting Robot. A Logical Design Using Digital and Analog Circuitry", May 111999.

[13] Chris Flesher, Devona Williams, Sean Benbrook, Somendra Sreedhar "Fire Protection Robot. Final Report" p. 1-78, 2004. 